\title{
Molar incisor hypomineralization in the permanent dentition of patients with unilateral or bilateral cleft lip and palate versus controls
}

\author{
Eman Allam ${ }^{1,2}$, Ahmed Ghoneima ${ }^{1,3}$, George Eckert ${ }^{4}$, Sunil Tholpady ${ }^{5}$, Carrie Klene ${ }^{6}$ and Katherine Kula $^{1 *}$ \\ ${ }^{1}$ Department of Orthodontics and Oral Facial Genetics, School of Dentistry, Indiana University, Indianapolis, IN, USA \\ ${ }^{2}$ Oral and Dental Research Division, National Research Centre, Cairo, Egypt \\ ${ }^{3}$ Faculty of Dental Medicine, Al-Azhar University, Cairo, Egypt \\ ${ }^{4}$ Department of Biostatistics, School of Medicine, Indiana University, Indianapolis, IN, USA \\ ${ }^{5}$ Division of Plastic Surgery, Department of Surgery, Indiana University, Indianapolis, IN, USA \\ ${ }^{6}$ Department of Oral Surgery and Hospital Dentistry, School of Dentistry, Indiana University, Indianapolis, IN, USA
}

\begin{abstract}
Purpose: Molar Incisor Hypomineralization (MIH) is a congenital defect of unknown etiology that has been recently identified and is currently considered an increasing concern to dental clinicians. The defect involves enamel mineralization of one to four permanent first molars usually associated with similarly affected permanent incisors. The purpose of this retrospective study was to investigate the prevalence, severity, and location of $\mathrm{MIH}$ in the permanent molars and incisors of patients with unilateral and bilateral cleft lip and palate (CLP) as compared with controls.

Methods: The sample consisted of intra-oral photographs of 71 CLP patients which were divided into two groups (unilateral versus bilateral cleft) and a modified Weerheijm ranking of enamel defects was compared to a control sample of 60 children without CLP who were age matched. Pearson chi-square tests were used to compare the groups for differences in the presence of hypomineralization, and Mantel-Haenszel chi-square tests were used to compare the groups for differences in MIH scores. Cochran-Mantel-Haenszel chi-square tests for stratified categorical data were used to compare the cleft and non-cleft sides for differences in the prevalence of hypomineralization and MIH scores within the CLP unilateral subjects. Significance was defined as $\mathrm{p}<0.05$.
\end{abstract}

Results: MIH scores were significantly lower for controls than for CLP bilateral and CLP unilateral groups ( $p<.0001)$. CLP bilateral had significantly higher MIH scores than CLP unilateral ( $\mathrm{p} \leq 0.01$ ). The MIH scores were not significantly different between the cleft and non-cleft sides in the CLP unilateral subjects. However, two of the individual teeth - the maxillary-lateral $(\mathrm{p}=0.03)$ and maxillary central incisors $(\mathrm{p} \leq 0.01)$ - did show significantly higher scores for the cleft side as compared with the non-cleft side.

Conclusions: Cleft patients are at higher risk of $\mathrm{MIH}$ than controls and children with bilateral clefts present with the most severe hypomineralization.

\section{Introduction}

Cleft lip and palate (CLP) is one of the most common craniofacial congenital malformations. In children affected with clefts, dental abnormalities in number, size, shape, structure, and eruption pattern are more frequent than in the general population [1]. Children with clefts may present with hypodontia, supernumerary teeth, peg-shaped teeth, crown and root malformations, dental asymmetry, and delay in tooth development $[2,3]$. Both deciduous and permanent dentitions are affected. The lateral incisor in the region of the alveolar cleft is the most sensitive to developmental disorders although other teeth are frequently affected $[2,3]$.

Dental enamel, an ectodermally derived, calcified tissue, forms the visible part of the tooth. Once formed, metabolic activity ceases, and developmental disorders manifest as permanent defects in the enamel. Disruption in the calcification or maturation processes produces structurally defective enamel (hypomineralization) [4,5]. If hypomineralization is so severe as to allow enamel surface layer breakdown, hypoplasia occurs. Some observations suggest an association between CLP and enamel defects [6-9]. The etiology of the enamel defects is unknown; however, due to the close chronologic correlation between development of the face and the tooth germs, it is assumed that systemic aspects may affect either event or that both events are related [7]. Recently, a particular pattern of structural enamel defects has been defined in the literature termed 'molar-incisor hypomineralization' (MIH) [10-12].

Etiological factors, for instance: low birth weight, calcium/ phosphate metabolic disturbances, and frequent childhood diseases

Correspondence to: Katherine Kula, Department of Orthodontics and Oral Facial Genetics, Indiana University School of Dentistry, 1121 W. Michigan St., Indianapolis, IN 46202, Tel: 317-278-9915; E-mail: kkula@iu.edu

Keywords: Cleft lip and palate, hypoplasia, molar incisor hypomineralization Received: June 01, 2015; Accepted: July 10, 2015; Published: July 13, 2015 
with high fever are associated with MIH $[11,12]$. CLP as well as the surgical treatment are also reported to be associated with MIH [10,1215]. Since hypomineralization of teeth can influence esthetics and caries experience, the dental status of children with cleft lip and palate (CLP) should be examined to better plan future expenditures for dental treatment. The purpose of this retrospective study was to investigate the prevalence, severity, and location of MIH in the permanent molars and incisors of patients with unilateral and bilateral cleft lip and palate (CLP) as compared with controls.

\section{Materials and methods}

The study was approved by the Institutional Review Board of Indiana University Purdue University Indianapolis. The sample consisted of 71 non-syndromic CLP subjects who were further divided into either Group 1 (unilateral CLP, $\mathrm{n}=47$ ) or Group 2 (bilateral CLP, $\mathrm{n}=24$ ) and a control sample (Group 3, $n=60$ ) of children without CLP who were age matched to the CLP subjects. The sample included both genders, aged 6 to 15 years. Measures of molar incisor hypomineralization as seen from the photographs were compared amongst the groups and within the unilateral CLP. Patient records were deidentified and coded.

Records were retrieved from the archives of the Department of Orthodontics and Oral Facial Genetics, Indiana University School of Dentistry (IUSD). The medical records were reviewed to identify significant medical histories. For each included subject, all erupted permanent incisors and first molars were evaluated using the frontal, buccal, and occlusal views on the intraoral photographs. Patients were not examined clinically. Data on cleft location, age, sex, and the presence or absence of MIH lesions were tabulated. A case was considered as having MIH when at least one molar or incisor was affected [16].

Exclusionary criteria included initial photographic records which did not include the first permanent molars as well as records which did not allow visual review of the incisors. Since many children with clefts have dental agenesis or impacted/un-erupted permanent incisors, these records were not excluded. All photographs were examined for MIH by a single calibrated examiner and data were recorded on standardized forms. The diagnosis of MIH was performed according to a modified criterion suggested by Weerheijm et al. [17]. The 4 first permanent molars and 8 permanent incisors were examined and recorded for the presence or absence of demarcated opacities, post-eruptive enamel breakdown, or atypical restorations [17].

The severity of lesions was recorded on a scale of (0-3) where a score of a 0 (zero) indicates a tooth with normal enamel structure while a score of 3 indicates severe enamel involvement or hypoplasia (Figures 1-3). Teeth with demarcated opacities with color shades of white, yellow, or brown which required no treatment were considered to have mild MIH (score 1). Moderate MIH included tooth lesions with rough and broken enamel surfaces (score 2); severe defects included the presence of hypomineralized lesions associated with loss of dental structure that may be affecting both enamel and dentin or an atypical restoration replacing affected hard tissue (score 3). In the current sample, there were no extracted first permanent molars. Due to the uncertainty of determining age-related eruptions versus extraction due to $\mathrm{MIH}$ or lack of supporting alveolar bone, missing incisors were not scored. Each tooth was examined by one investigator for the presence or absence of enamel defect and was given a score according to the degree of enamel involvement. Subjects' individual hypomineralization scores were defined by the most severe defect seen in their permanent first molars or incisors [18].

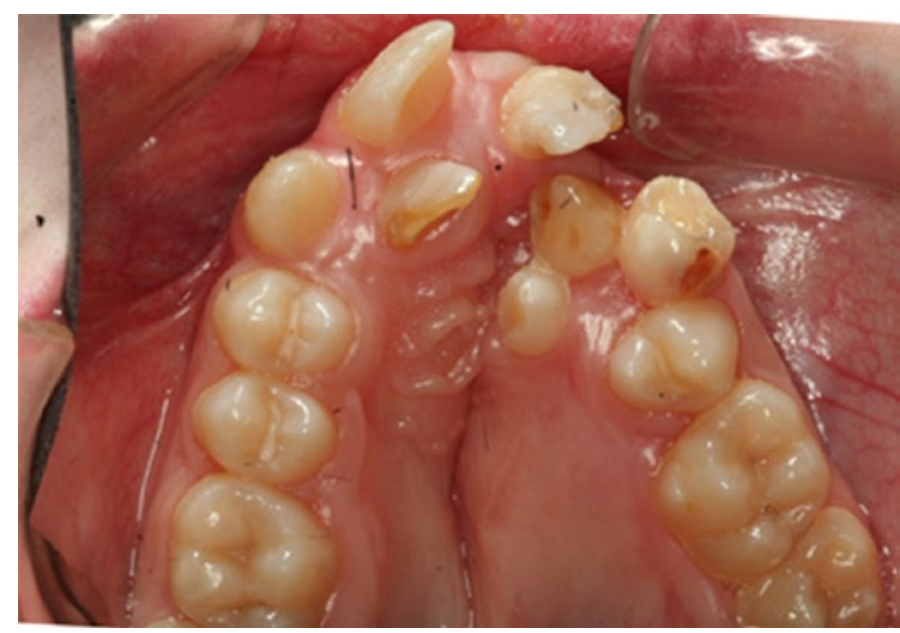

Figure 1. Clinical case of right lateral and left central incisors severely affected (score 3) by MIH in unilateral cleft patient.

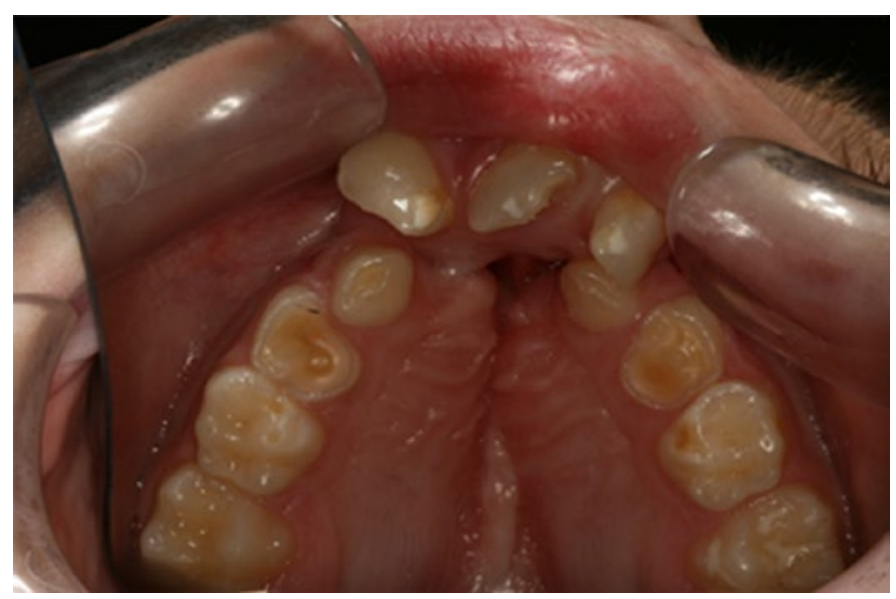

Figure 2. Postoperative enamel breakdown in tooth \#9 and demarcated opacity (score 3 ) in teeth \# 8 and 10 in a patient with bilateral CLP.

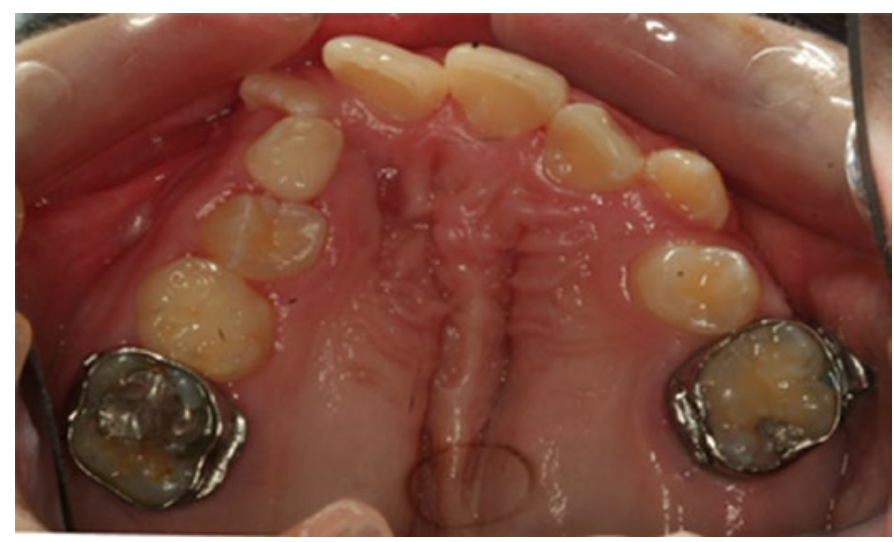

Figure 3. Severe MIH (score 3) in the form of a defective atypical restoration in tooth \#3 in unilateral CLP patient.

\section{Statistical analysis}

Twenty randomly selected cases were reevaluated by one investigator 1 week apart to ensure repeatability. Pearson chi-square tests were used to compare the CLP bilateral, CLP unilateral, and control groups for differences in the presence of any hypomineralization, and 
Mantel-Haenszel chi-square tests were used to compare the groups for differences in MIH scores. Cochran-Mantel-Haenszel chi-square tests for stratified categorical data were used to compare the cleft and non-cleft sides for differences in the prevalence of hypomineralization and MIH scores within the CLP unilateral subjects. Significance was defined as $\mathrm{p}<0.05$.

\section{Results}

High intra-rater reliability was reported with a kappa of 0.85 and a weighted kappa of 0.91 . Percentages of the severity of MIH in the affected teeth are presented in Figures 4-6. Comparisons among the groups showed that MIH scores were significantly lower for controls than for CLP bilateral and CLP unilateral groups $(\mathrm{p}<0.01)$. CLP bilateral had significantly higher MIH scores than CLP unilateral $(\mathrm{p}=0.01)$ but did not have a significant difference in the presence of any hypomineralization ( $\mathrm{p}=0.17)$. MIH scores for individual teeth $(\# 14,19$, $9,10,3,30,7$, and 8) were significantly lower for control than for CLP bilateral group (all $\mathrm{p} \leq 0.03)$ for any hypomineralization and $\mathrm{MIH}$ score. MIH scores for molars (\#14, 19, 30, and 7) were significantly lower for control than for CLP unilateral group (all $\mathrm{p} \leq 0.01$ ).
MIH scores for CLP bilateral and CLP unilateral-left side subjects were not significantly different for the left lateral and central incisors (teeth \#9 and $10, \mathrm{p}=0.78$ and $\mathrm{p}=0.70$, respectively); similarly, $\mathrm{MIH}$ scores for CLP bilateral and CLP unilateral-right side subjects were not significantly different for the right lateral and central incisors (teeth \#7 and $8, p=0.08$ and $p=0.27$, respectively). CLP bilateral had significantly higher MIH scores for teeth \# 9 and 10 than CLP unilateral-right side subjects ( $\mathrm{p}=0.01$ and $\mathrm{p}=0.03$, respectively) and significantly higher $\mathrm{MIH}$ scores for teeth \#7 and 8 than CLP unilateral-left side subjects ( $\mathrm{p}=0.01$ and $\mathrm{p}=0.01$ respectively). MIH scores were not different among groups for the mandibular incisors: teeth $\# 24,23,26$, or 25 (all p $>0.10$ ).

The MIH scores were not significantly different between the cleft and non-cleft sides in the CLP unilateral subjects. However, two of the individual teeth did show significantly higher scores for the cleft side the maxillary lateral $(\mathrm{p}=0.033)$ and maxillary central incisors $(\mathrm{p}=0.01)$ (Table 1).

\section{Discussion}

The results of our study on hypomineralization of permanent molars

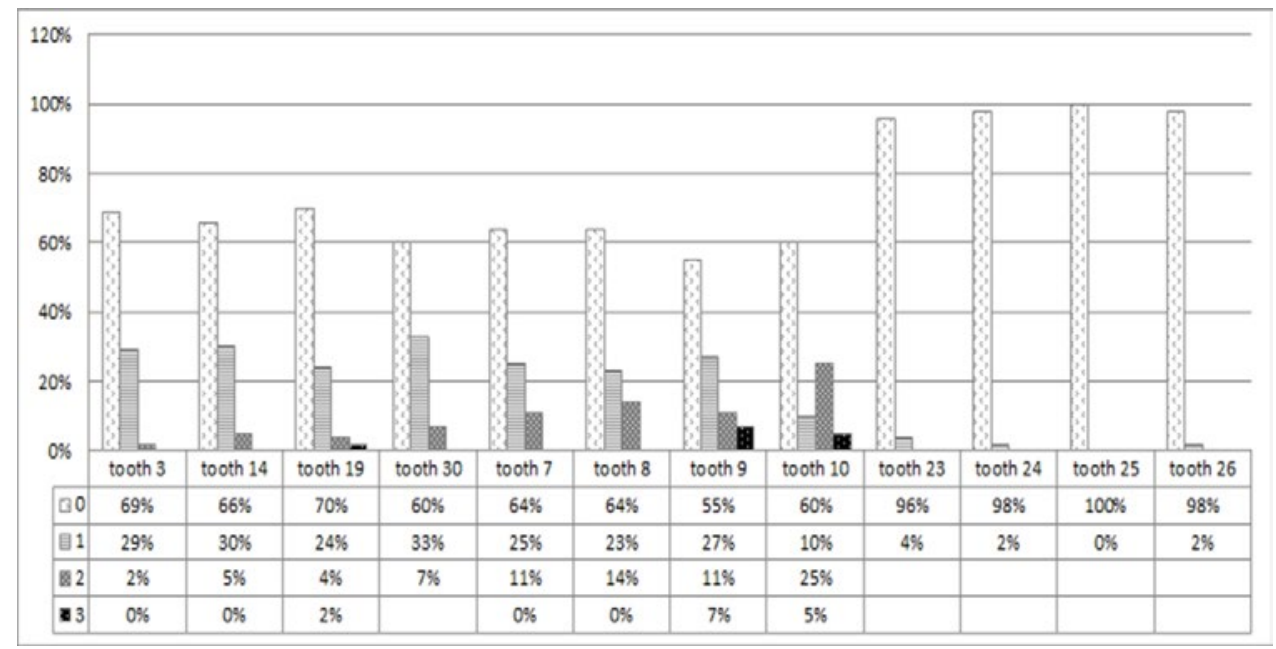

Figure 4. Percentage of severity of MIH in permanent first molars and incisors in unilateral CLP subjects.

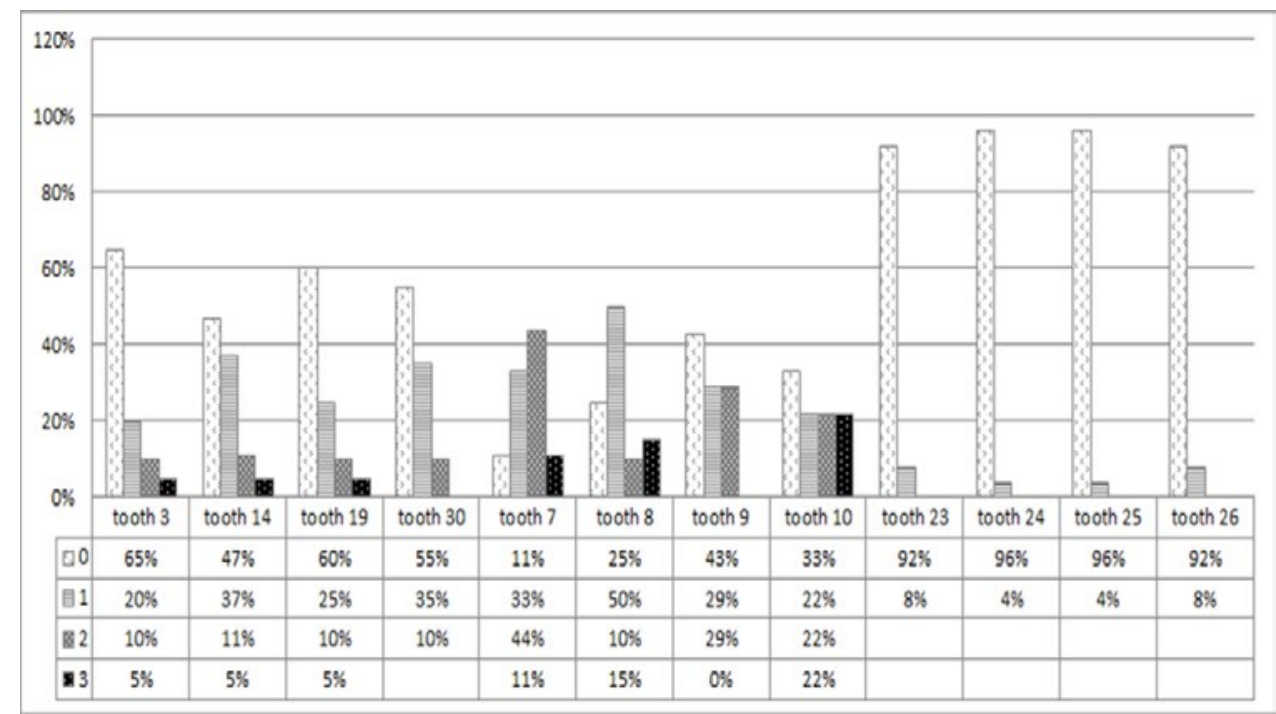

Figure 5. Percentage of severity of MIH in permanent first molars and incisors in bilateral CLP subjects. 


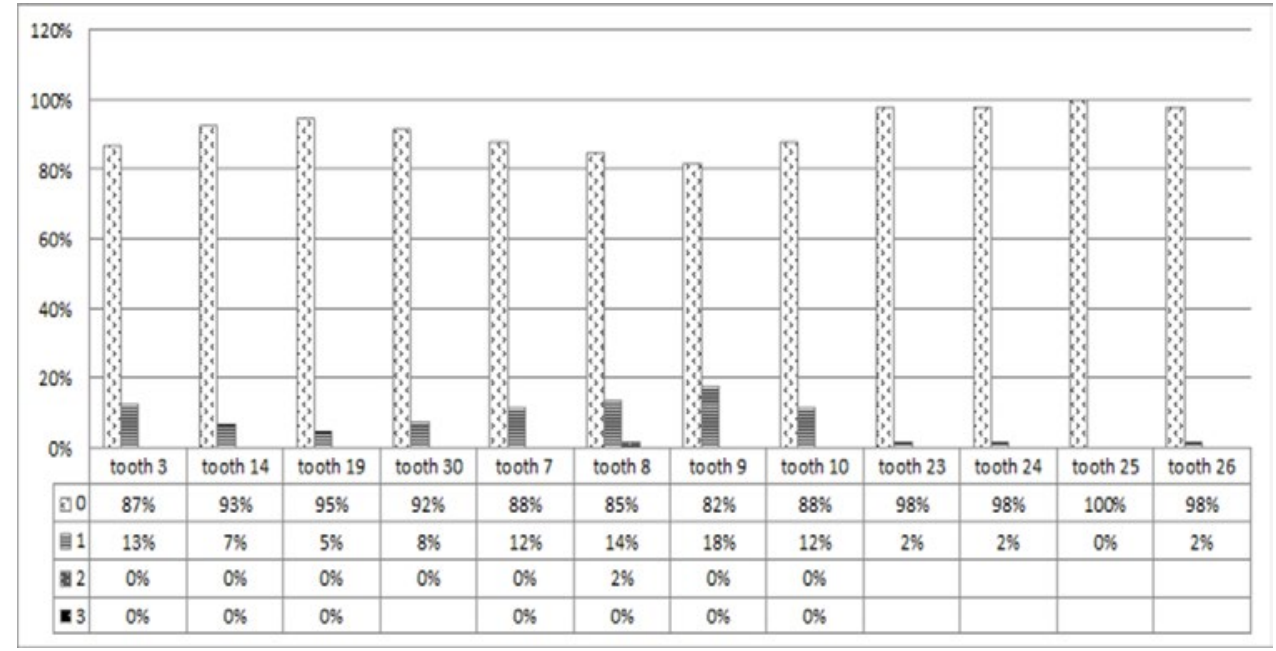

Figure 6. Percentage of severity of MIH in permanent first molars and incisors in control subjects.

Table 1. Comparison of MIH scores between the cleft and non-cleft sides in the CLP unilateral subjects with blank areas indicating no teeth with that score.MIH scores: $0=$ normal enamel structure; 1 = mild - demarcated opacities with color shades of white, yellow, or brown requiring no treatment; $2=$ moderate - rough and broken enamel surfaces; $3=$ Severe - loss of dental structure affecting both enamel and dentin possibly or an atypical restoration replacing affected hard tissue.

\begin{tabular}{|c|c|c|c|c|c|c|}
\hline & & & & $\begin{array}{l}\text { MIH Scor } \\
\text { No Cleft }\end{array}$ & & \\
\hline Half mouth & 0 & $9(19 \%)$ & $3(6 \%)$ & $0(0 \%)$ & $1(2 \%)$ & 0.16 \\
\hline & 1 & $4(9 \%)$ & $13(28 \%)$ & $2(4 \%)$ & $1(2 \%)$ & \\
\hline & 2 & $4(9 \%)$ & $3(6 \%)$ & $4(9 \%)$ & $0(0 \%)$ & \\
\hline & 3 & $0(0 \%)$ & $2(4 \%)$ & $1(2 \%)$ & $0(0 \%)$ & \\
\hline & Total & $17(36 \%)$ & $21(45 \%)$ & $7(15 \%)$ & $2(4 \%)$ & \\
\hline Maxillary first molar & 0 & $26(59 \%)$ & $3(7 \%)$ & $0(0 \%)$ & & 0.48 \\
\hline & 1 & $4(9 \%)$ & $9(20 \%)$ & $0(0 \%)$ & & \\
\hline & 2 & $0(0 \%)$ & $1(2 \%)$ & $1(2 \%)$ & & \\
\hline & Total & $30(68 \%)$ & $13(30 \%)$ & $1(2 \%)$ & & \\
\hline Mandibular first molar & 0 & $26(58 \%)$ & $4(9 \%)$ & $0(0 \%)$ & $0(0 \%)$ & 0.17 \\
\hline & 1 & $2(4 \%)$ & $8(18 \%)$ & $2(4 \%)$ & $1(2 \%)$ & \\
\hline & 2 & $0(0 \%)$ & $1(2 \%)$ & $1(2 \%)$ & $0(0 \%)$ & \\
\hline & Total & $28(62 \%)$ & $13(29 \%)$ & $3(7 \%)$ & $1(2 \%)$ & \\
\hline Maxillary lateral incisor & 0 & $6(43 \%)$ & $0(0 \%)$ & $0(0 \%)$ & & $0.03 *$ \\
\hline & 1 & $2(14 \%)$ & $1(7 \%)$ & $0(0 \%)$ & & \\
\hline & 2 & $3(21 \%)$ & $0(0 \%)$ & $2(14 \%)$ & & \\
\hline & Total & $11(79 \%)$ & $1(7 \%)$ & $2(14 \%)$ & & \\
\hline Maxillary central incisor & 0 & $17(41 \%)$ & $0(0 \%)$ & $1(2 \%)$ & $0(0 \%)$ & $0.00 *$ \\
\hline & 1 & $8(20 \%)$ & $4(10 \%)$ & $0(0 \%)$ & $0(0 \%)$ & \\
\hline & 2 & $4(10 \%)$ & $2(5 \%)$ & $2(5 \%)$ & $0(0 \%)$ & \\
\hline & 3 & $1(2 \%)$ & $2(5 \%)$ & $0(0 \%)$ & $0(0 \%)$ & \\
\hline & Total & $30(73 \%)$ & $8(20 \%)$ & $3(7 \%)$ & $0(0 \%)$ & \\
\hline Mandibular lateral incisor & 0 & $42(93 \%)$ & $1(2 \%)$ & & & 0.56 \\
\hline & 1 & $2(4 \%)$ & $0(0 \%)$ & & & \\
\hline & Total & $44(98 \%)$ & $1(2 \%)$ & & & \\
\hline Mandibular central incisor & 0 & $46(98 \%)$ & & & & 0.32 \\
\hline & 1 & $1(2 \%)$ & & & & \\
\hline & Total & $47(100 \%)$ & & & & \\
\hline
\end{tabular}

*Significant at the .05 level, Cochran-Mantel-Haenszel chi-square test for stratified categorical data

and incisors in children with CLP confirm other reports concerning dental anomalies, such as variations and defects in teeth structure are frequently reported among children with unilateral and bilateral CLP. These defects exist in both teeth located in the vicinity of the cleft as well as away from the cleft area [19-21]. The permanent maxillary lateral incisor has been reported to be the most affected tooth suggesting that its location close to the cleft is a causative factor [19]. However, it is difficult to determine the amount of influence of the multi-factorial process of the clefting, the surgical treatment, or the inflammatory process of cleft lip repair on the malformation of the maxillary incisors. 
The congenital absence of the cleft-side lateral incisor is the most common finding in children with cleft followed by the presence of a supernumerary tooth in the cleft side and alterations in shape and structure [19,21]. Literature has also described an association between CLP and enamel defects [6-9]. A recently designated form of enamel defect named MIH has been identified by the European Academy of Pediatric Dentistry as the developmentally derived dental defect that involves hypomineralization of 1 to 4 permanent first molars that is frequently associated with similarly affected permanent incisors [1012,22]. The aim of the current study was to determine, in a specific population of CLP, the prevalence and the severity of MIH defects in the permanent dentition of patients with unilateral and bilateral CLP, as well as to study the relation with the cleft side.

The published evidence regarding dental anomalies associated with clefts is based mostly on studies that analyze a heterogeneous population of children with clefts. Such a sample may limit the ability to associate a cleft type with a particular dental anomaly. In our current study, patients were stratified into either unilateral or bilateral CLP in order to be able to better determine the pattern of association and showed that the more severe bilateral CLP had more severe hypomineralization than the unilateral CLP.

The criteria for the diagnosis of MIH was developed by Weerheijm et al. [17] and was based on the clinical identification of demarcated opacities, post-eruption breakdown, atypical restorations, and extracted permanent first molars (PFMs) due to MIH. Dentitions with generalized opacities present on all teeth (such as in several forms of amelogenesis imperfecta), rather than limited to the permanent molars and incisors, were not considered to have MIH. Demarcated opacities with distinct boundaries were described as defects of altered enamel translucency where the defective enamel is usually white-cream or yellow-brown in color and of normal thickness with a smooth surface. In most MIH cases, the opacities are generally limited to the incisal or cuspal one third of the crown $[16,17,23]$.

Currently, only limited data are available on the prevalence of $\mathrm{MIH}$ as comparable and representative prevalence studies are lacking. According to the existing information, the prevalence of $\mathrm{MIH}$ varies between 2.9 and $25 \%$ depending on the country and the age of the studied sample $[16,18,22,23]$. In a retrospective population study of nine-year-old Dutch children, $14.3 \%$ of the children had at least one affected tooth with a hypomineralization defect with $55.6 \%$ of those children presenting with only mild MIH or demarcated opacities [16]. In a group of Greek children aged 5 to 12 years old, the prevalence was reported to be $10.2 \%$ [22]. In Brazilian children, $\mathrm{MIH}$ was detected in $19.8 \%$ of the sample selected from children living in both rural and urban areas across the country. The majority of the defects present were also mild, with only demarcated opacities without post-eruptive structural loss [18]. In our current study, $83.1 \%$ of the children with CLP had some form of enamel hypomineralization compared to $23.3 \%$ in the control group. This indicates that cleft patients are at higher risk of MIH than the controls. These data are consistent with those of Dahllof et al. [24] who demonstrated that children with clefts exhibited a significantly increased number of decayed and filled carious surfaces compared with children without clefts [24].

Among the CLP sample, $75 \%$ of the bilateral and 39\% of the unilateral cleft subjects had moderate to severe enamel defects. MIH scores were significantly higher in patients with bilateral than unilateral CLP suggesting that children with bilateral clefts may present with more severe involvement. Comparisons between the cleft and non- cleft sides in unilateral CLP showed non-significant differences in MIH scores except for the maxillary lateral and central incisors. This could be explained by the fact that the maxillary lateral and central incisors, being the closest to the cleft, are the teeth most commonly affected in CLP [25].

MIH scores in bilateral cleft subjects were non-significantly different from the cleft side and significantly higher than the non-cleft side in unilateral cleft subjects. This observation was in agreement with other reports showing that dental anomalies in general are more frequent on the cleft side in unilateral CLP patients [25-27]. This also indicates that the location of the tooth in relation to the cleft is a factor that significantly contributes to the degree of involvement of developmental defect in enamel.

In enamel hypomineralization, the enamel is characterized by higher porosity and lower mechanical resistance than unaffected teeth rendering the affected tooth more susceptible to decay. In addition, MIH predisposes patients to other dental problems, such as hypersensitivity, pain, caries, erosion, and poor oral health in addition to the esthetic concerns. These subjects thus require excessive dental care and prevention programs should be directed at these vulnerable populations [28-30].

The limitation of this study is that intraoral photographs, not clinical examinations, were used to evaluate hypomineralization. However, it was difficult to identify a large group of subjects with CLP to examine prospectively and to maintain investigator reliability over a long time. Thus, intraoral photographs required to be high quality for purposes of orthodontic records were used retrospectively.

This study demonstrated a high prevalence of MIH among patients with CLP and confirms that those subjects are at potentially higher risk for caries and tooth decay. Clinicians thus involved in the treatment and rehabilitation process for these patients should take this into consideration and should support caries prevention protocols. In addition, the authors stress the necessity of reevaluating the criteria of diagnosing and scoring MIH subjects. The MIH scoring system currently used does not indicate the extent of hypomineralization since this cannot be based solely on the most severely affected tooth. A wellestablished set of criteria that can truly describe the degree of enamel involvement is necessary for clinicians to be able to clearly distinguish and differentiate lesion type and severity in cleft patients.

\section{References}

1. Ranta R (1986) A review of tooth formation in children with cleft lip/palate. Am $J$ Orthod Dentofacial Orthop 90: 11-18. [Crossref]

2. Vichi M, Franchi L (1995) Abnormalities of the maxillary incisors in children with cleft lip and palate. ASDC J Dent Child 62: 412-417. [Crossref]

3. Tereza GPG, de Carvalho Carrara CF, Costa B (2010) Tooth abnormalities of number and position in the permanent dentition of patients with complete bilateral cleft lip and palate. Cleft Palate Craniofac J 47: 247-252. [Crossref]

4. van Amerongen WE, Kreulen CM (1995) Cheese molars: a pilot study of the etiology of hypocalcifications in first permanent molars. ASDC $J$ Dent Child 62: 266-269. [Crossref]

5. Jälevik B, Norén JG (2000) Enamel hypomineralization of permanent first molars: a morphological study and survey of possible aetiological factors. Int J Paediatr Dent 10: 278-289. [Crossref]

6. Dixon DA (1968) Defects of structure and formation of the teeth in persons with cleft palate and the effect of reparative surgery on the dental tissues. Oral Surg Oral Med Oral Pathol 25: 435-446. [Crossref] 
7. Malanczuk T, Opitz C, Retzlaff R (1999) Structural changes of dental enamel in both dentitions of cleft lip and palate patients. J Orofac Orthop 60: 259-268. [Crossref]

8. Chapple JR, Nunn JH (2001) The oral health of children with clefts of the lip, palate, or both. Cleft Palate Craniofac J 38: 525-528. [Crossref]

9. Maciel SP, Costa B, Gomide MR (2005) Difference in the prevalence of enamel alterations affecting central incisors of children with complete unilateral cleft lip and palate. Cleft Palate Craniofac J 42: 392-395. [Crossref]

10. Weerheijm KL, Jälevik B, Alaluusua S (2001) Molar-incisor hypomineralisation. Caries Res 35: 390-391. [Crossref]

11. Weerheijm KL1 (2003) Molar incisor hypomineralisation (MIH). Eur J Paediatr Den 4: 114-120. [Crossref]

12. Crombie F, Manton D, Kilpatrick N (2009) Aetiology of molar-incisor hypomineralization: a critical review. Int J Paediatr Dent 19: 73-83. [Crossref]

13. William V, Messer LB, Burrow MF (2006) Molar incisor hypomineralization: review and recommendations for clinical management. Pediatr Dent 28: 224-232. [Crossref]

14. Mathu-Muju K, Wright JT (2006) Diagnosis and treatment of molar incisor hypomineralization. Compend Contin Educ Dent 27: 604-610. [Crossref]

15. Whatling R, Fearne JM (2008) Molar incisor hypomineralization: a study of aetiological factors in a group of UK children. Int J Paediatr Dent 18: 155-162. [Crossref]

16. Jasulaityte L, Weerheijm KL, Veerkamp JS (2008) Prevalence of molar-incisorhypomineralisation among children participating in the Dutch National Epidemiological Survey (2003). Eur Arch Paediatr Dent 9: 218-223. [Crossref]

17. Weerheijm KL, Duggal M, Mejàre I, Papagiannoulis L, Koch G, et al. (2003) Judgement criteria for molar incisor hypomineralisation (MIH) in epidemiologic studies: a summary of the European meeting on MIH held in Athens, 2003. Eur J Paediatr Dent 4: 110-113. [Crossref]

18. da Costa-Silva CM, Jeremias F, de Souza JF, Cordeiro Rde C, Santos-Pinto L, Zuanon AC (2010). Molar incisor hypomineralization: prevalence, severity and clinical consequences in Brazilian children. Int J Paediatr Dent 20: 426-34.

19. Lourenço Ribeiro L, Teixeira Das Neves L, Costa B, Ribeiro Gomide M (2003) Dental anomalies of the permanent lateral incisors and prevalence of hypodontia outside the cleft area in complete unilateral cleft lip and palate. Cleft Palate Craniofac J 40: 172 175. [Crossref]

20. Menezes R, Vieira AR (2008) Dental anomalies as part of the cleft spectrum. Cleft Palate Craniofac J 45: 414-419. [Crossref]

21. Al Jamal GA, Hazza'a AM, Rawashdeh MA (2010) Prevalence of dental anomalies in a population of cleft lip and palate patients. Cleft Palate Craniofac J 47: 413-420. [Crossref]

22. Lygidakis NA, Dimou G, Marinou D (2008) Molar-incisor-hypomineralisation (MIH) A retrospective clinical study in Greek children. II. Possible medical aetiological factors. Euro Arch Paediatr Dent 9: 207-217.

23. Jälevik B1 (2010) Prevalence and diagnosis of molar-incisor-hypomineralisation (MIH): A systematic review. Eur Arch Paediatr Dent 11: 59-64. [Crossref]

24. Dahllöf G, Ussisoo-Joandi R, Ideberg M, Modeer T (1989) Caries, gingivitis, and dental abnormalities in preschool children with cleft lip and/or palate. Cleft Palate $J$ 26: 233-237. [Crossref]

25. Lourenço Ribeiro L, Teixeira Das Neves L, Costa B, Ribeiro Gomide M (2003) Denta anomalies of the permanent lateral incisors and prevalence of hypodontia outside the cleft area in complete unilateral cleft lip and palate. Cleft Palate Craniofac J 40: 172175. [Crossref]

26. Vichi M, Franchi L (1995) Abnormalities of the maxillary incisors in children with cleft lip and palate. ASDC J Dent Child 62: 412-417. [Crossref]

27. Akcam MO, Evirgen S, Uslu O, MemikoÄŸlu UT (2010) Dental anomalies in individuals with cleft lip and/or palate. Eur J Orthod 32: 207-213. [Crossref]

28. Mast P, Rodrigueztapia MT, Daeniker L, Krejci I (2013) Understanding MIH definition, epidemiology, differential diagnosis and new treatment guidelines. Eur $J$ Paediatr Dent 14: 204-208. [Crossref]

29. Lynch RJ1 (2013) The primary and mixed dentition, post-eruptive enamel maturation and dental caries: a review. Int Dent $J 63$ Suppl 2: 3-13. [Crossref]

30. Willmott NS, Bryan RA, Duggal MS (2008) Molar-incisor-hypomineralisation: a literature review. Eur Arch Paediatr Dent 9: 172-179. [Crossref]

Copyright: (C2015 Allam E. This is an open-access article distributed under the terms of the Creative Commons Attribution License, which permits unrestricted use, distribution, and reproduction in any medium, provided the original author and source are credited. 